\title{
Consideraciones sobre la Universidad Pública ${ }^{1}$
}

\author{
Por Alejandro Berrotarán*
}

En el discurso de muchos de los egresados de nuestras universidades públicas se evidencian ciertas ideas de meritocracia. Estas plantean que los logros y éxitos personales son producto exclusivo del esfuerzo del individuo. Quienes las suscriben, orgullosos exhiben su título como premio merecido a su sacrificio. En el mejor de los casos, reconocen y agradecen a su círculo cercano de amigos, familiares y docentes, que colaboraron en su carrera individual. Existe en estas personas una suerte de amnesia. Olvidan que sus estudios son gratuitos gracias a las miles de manos invisibles que montan y sostienen nuestras universidades.

Mantener económicamente una educación superior pública y gratuita implica un enorme sacrificio para nuestro pueblo ${ }^{2}$. Más significativo aun es este esfuerzo colectivo en una sociedad, como la nuestra, que presenta preocupantes niveles de pobreza y desigualdad económica ${ }^{3}$. Esta realidad repercute directamente sobre las posibilidades de educación de las personas, ocasionando que las oportunidades efectivas de iniciar y concluir una carrera universitaria sean remotas para una buena parte de la población ${ }^{4}$. Pero la injusticia que esta situación supone es aún más grave. Paradójicamente, son justamente los sectores de menores ingresos, que no acceden a la universidad, los que soportan la carga más pesada en el sostenimiento económico de estos estudios ${ }^{5}$.

1 Esta nota de opinión fue elaborada en base al discurso que realice en el acto de egreso de la Facultad de Derecho el 7 de julio del 2017. Disponible online en https://youtu.be/KCi9ztnG0kk (último acceso el día 15 de agosto de 2017).

2 De acuerdo al informe realizado por el Centro de Estudios de la Educación Argentina de la Universidad de Belgrano el presupuesto promedio por alumno de una universidad pública nacional es de 3114 dólares anuales (datos elaborados en base al presupuesto nacional del 2016). Informe disponible en www.ub.edu.ar/centros_de_estudio/cea/cea_numero_48.pdf (último acceso el día 15 de agosto de 2017).

3 De acuerdo al INDEC, la pobreza alcanza al 30,3\% de la población nacional y la brecha entre ingreso familiar promedio del $10 \%$ de los hogares más pobres y el $10 \%$ más rico es de 21,8 veces (datos del primer trimestre de 2017). Informe disponible en www.indec.gob.ar/uploads/informesdeprensa/ingresos_1trim17.pdf (último acceso el día 15 de agosto de 2017).

4 "La educación superior y universitaria es pro-rica: a mayor ingreso, mayor gasto imputado. El quintil más pobre recibe el 11,8 \% del gasto en educación superior y universitaria, mientras que el quintil más rico recibe el 29,7\%" (datos de 2010). Informe disponible en: http://blogs.eco.unc.edu.ar/jifp/files/47JIFP-RosanaJanCasa\%C3\%B1o.pdf (último acceso el día 15 de agosto de 2017).

5 Mientras que el $20 \%$ de la población con ingresos más bajos paga en impuestos, en promedio, el 49,6\% de sus ingresos, el $70 \%$ de la población con ingresos intermedios paga, en 
Si creemos en la igualdad, no podemos tolerar las disparidades presentes en el acceso a los estudios universitarios. Las políticas dirigidas hacia los sectores sociales más desfavorecidos para posibilitarles el ingreso a la educación superior son una herramienta fundamental para cambiar esta situación. Nuestras casas de estudio deben llevar a cabo políticas que tiendan a una ampliación social de la matrícula universitaria, y que posibiliten la permanecía y egreso de los estudiantes. Para esto, son necesarios cambios estructurales y reformas profundas.

Pero no solamente debemos preocuparnos por quienes acceden a nuestras aulas. Debemos también preguntarnos al servicio de quiénes están diseñados los contenidos de nuestras carreras y qué deberes tenemos los profesionales que nos egresamos de ellas. Hacernos estas preguntan nos permitirá responder ¿por qué nuestra sociedad debe soportar la carga de contribuir económicamente con la universidad pública?

A partir de esta pregunta, es razonable cuestionarnos el rol del egresado de la universidad pública. Así, se vuelve objeto de análisis el perfil profesional presente en nuestras currículas. ¿De qué sirve que se formen profesionales con contenidos que omiten los problemas de quienes sostienen nuestra educación? La universidad no es una isla sino que forma parte de una comunidad más amplia a la que integra. La universidad debe abrir sus puertas y escuchar las voces silenciadas de nuestro pueblo. Es preciso fortalecer programas, proyectos y acciones dirigidas a la comunidad de acuerdo a los diagnósticos, las demandas y las problemáticas planteadas que requieren de nuestra atención. Los planes de estudio deben traducir las necesidades de nuestra comunidad. Las facultades deben vestirse de obrero, de desempleado, de negro, de campesino, de excluido. El perfil profesional del egresado de nuestras aulas debe estar atravesado por las necesidades de nuestra sociedad y, en especial, por las de aquellos sectores más desfavorecidos que no acceden a nuestras aulas.

Tenemos además, como egresados, un deber ligado a la vocación de servicio público que hay mantener presente. Existe un pueblo que necesita el compromiso de nuestros profesionales con sus causas. En este sentido, todo egresado que realizó sus estudios en una universidad pública tiene un deber general de servir en los asuntos de interés público. Los abogados tenemos esta obligación general pero también responsabilidades específicas ligadas al papel que como profesionales desempeñamos. Así, desde el lugar que ocupemos, tenemos que mejorar el Derecho, acercarlo a la sociedad y garantizar el acceso pleno a la justicia. Una práctica del Derecho sensible al interés público justifica el status otorgado al abogado y la inversión que significa nuestra formación.

promedio, el 43,8 \% de sus ingresos, y el $10 \%$ con los ingresos más altos soporta una presión tributaria del $47 \%$ de sus ingresos (datos de 2010). Informe disponible en: www.idaes.edu.ar/papelesdetrabajo/paginas/Documentos/n15/Rossignolo.pdf (último acceso el día 15 de agosto de 2017). 
Los egresados de universidades públicas somos privilegiados que nos hemos beneficiado del esfuerzo ajeno. Una sociedad ha subsidiado nuestros estudios. Por ello, nuestro título refleja no solamente nuestro esfuerzo individual, sino el esfuerzo de un pueblo que espera mucho de nosotros. Son vastos los sectores marginados de nuestra sociedad que requieren nuestros servicios y para saldar nuestra deuda con ellos contamos con las herramientas que nuestra formación nos otorgó.

Nuestro compromiso con la defensa de la universidad pública y gratuita no se limita a oponernos a su arancelamiento sino que implica un compromiso con un perfil de egresado y un desarrollo profesional abocado a los que menos tienen. Por eso, tengamos presentes a quienes sin estar en nuestras aulas nos permiten estar a nosotros. A ellos, a los humildes de esta tierra, nos debemos.

*Abogado de la Universidad Nacional de Córdoba 